\title{
COLLIMATION SYSTEM DESIGN FOR BEAM LOSS LOCALIZATION WITH SLIPSTACKING INJECTION IN THE FERMILAB MAIN INJECTOR*
}

\author{
A.I. Drozhdin ${ }^{\dagger}$, B. C. Brown, D.E. Johnson, K. Koba, I. Kourbanis, \\ N.V. Mokhov, I.L. Rakhno, V.I. Sidorov, FNAL, Batavia, IL 60510, USA
}

\section{Abstract}

Results of modeling with the 3-D STRUCT and MARS15 codes of beam loss localization and related radiation effects are presented for the slipstacking injection to the Fermilab Main Injector. Simulations of proton beam loss are done using multi-turn tracking with realistic accelerator apertures, nonlinear fields in the accelerator magnets and time function of the RF manipulations to explain the results of beam loss measurements. The collimation system consists of one primary and four secondary collimators. It intercepts a beam power of $1.6 \mathrm{~kW}$ at a scraping rate of $5 \%$ of $5.5 \mathrm{E}+13 \mathrm{ppp}$, with a beam loss rate in the ring outside the collimation region of $1 \mathrm{~W} / \mathrm{m}$ or less. Based on thorough energy deposition and radiation modeling, a corresponding collimator design was developed that satisfies all the radiation and engineering constraints.

\section{BEAM LOSS AT SLIP-STACKING INJECTION}

The Main Injector has a challenge for future intensity increase via slip-stacking of two proton multi-batch beams from the Booster at $8 \mathrm{GeV}$.

Simulations of particle loss at a slip-stacking injection to the Main Injector are done using multi-turn tracking with STRUCT [1] code in realistic conditions. In the simulations, the injection consists of three steps:

- first beam injection and capture to a $0.1 \mathrm{MV}$ separatrix at the central trajectory during 1000 turns followed by beam displacement on RF frequency by $-1300 \mathrm{~Hz}$ during 4000 turns;

- second beam injection during 2000 turns followed by displacement in RF frequency of both beams by $+650 \mathrm{~Hz}$ during 2000 turns. At the end of this step both beams are equidistant from the equilibrium orbit;

- and finally, capture of two beams to a common $1 \mathrm{MV}$ separatrix and acceleration during 6500 turns. During the third step, particles lost from 0.1 MV separatrixes during first two steps may be captured to $1 \mathrm{MV}$ separatrixes adjacent to the main ones, developing parasitic bunches.

The simulation finds that particle loss occurs mostly from the parasitic separatrixes, It matches the loss rate of $3 \%-5 \%$ and the measured time distribution of losses.

Population of lost particles at the Lambertson magnets and beam pipe aperture during capture to the main separatrix at the slip-stacking injection (top), momentum distribu-

\footnotetext{
* Work supported by the Universities Research Association, Inc., under contract DE-AC02-76CH03000 with the U. S. Department of Energy.

$\dagger$ drozhdin@fnal.gov
}
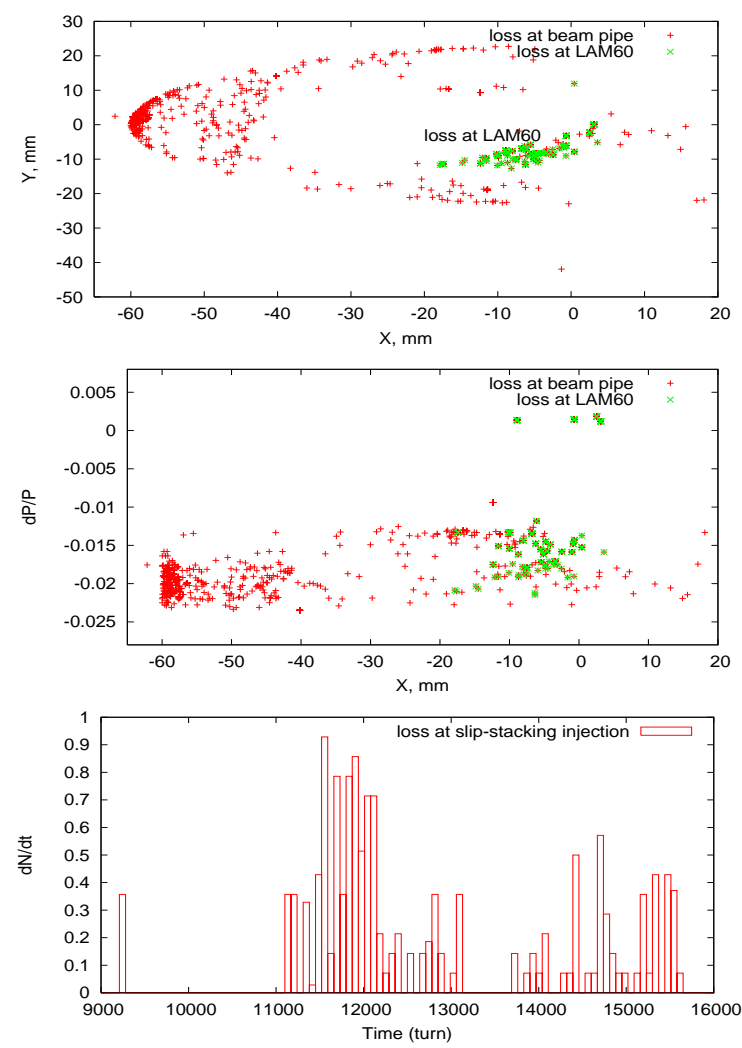

Figure 1: Particles, lost at slip-stacking injection.

tions (middle) and time ditribution of particle loss (bottom) are presented in Fig. 1. Distribution of losses along the ring is shown in Fig. 2. Calculations are done with nonlinear fields in the main dipole and quadrupole magnets including skew harmonics. $3.9 \%$ of the beam is lost with $31 \%$ of this amount lost from the main and $69 \%$ from parasitic separatrix. Much of the loss is at extraction Lambertson magnets; $29 \%$ of particles at MI60, 3.5\% at the MI40 beam abort and $1.5 \%$ - at MI52. The remaining $34 \%$ are distributed along the accelerator.

\section{COLLIMATION SYSTEM PERFORMANCE}

As shown in a middle of Fig. 1, most of particles are lost at slip-stacking injection in a horizontal plane with $\mathrm{dP} / \mathrm{P}=-$ 0.02 . This result is in a good agreement with the measurements in the machine. Because of this the collimation system is designed to intercept particles only in a horizontal plane. A two-stage collimation system consists of one single-jaw horizontal primary and four secondary L-shape collimators. The horizontal secondary collimators are lo- 


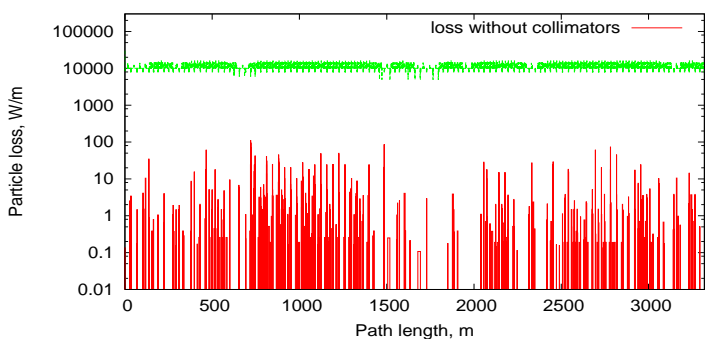

Figure 2: Particle loss distribution along the Main Injector at slip-stacking injection.

cated at the beginning and at the end of the MI30 straight section, leaving the middle part of MI30 with low losses to protect the very sensitive electron cooling system.

Table 1: Collimator jaws position.

\begin{tabular}{|c|c|c|c||c|c|}
\hline coll. & length & $\begin{array}{c}\text { half-size envelope } \\
40 \text { X 20mm-mrad } \\
\text { collim. entrance }\end{array}$ & \multicolumn{2}{|c|}{$\begin{array}{c}\text { collimator entrance } \\
\text { w/r to beam pipe center }\end{array}$} \\
\hline & & hor. & ver. & $\begin{array}{c}\text { hor./ver. } \\
\text { position }\end{array}$ & $\begin{array}{c}\text { hor./ver. } \\
\text { angle }\end{array}$ \\
\hline & $\mathrm{m}$ & $\mathrm{mm}$ & $\mathrm{mm}$ & $\mathrm{mm}$ & $\mathrm{mrad}$ \\
\hline PrH. & 0.0005 & 12.69 & 4.12 & $-27.5827 / 0$ & - \\
S1a & 0.3631 & 7.17 & 10.56 & $21.55 / 16.96$ & $-16.335 /-17.998$ \\
S1 & 1.278 & 7.17 & 10.56 & $15.62 / 10.42$ & $1.181 /-0.511$ \\
S2a & 0.3631 & 7.25 & 9.90 & $17.59 / 17.03$ & $-17.458 /-17.913$ \\
S2 & 1.278 & 7.25 & 9.90 & $11.25 / 10.53$ & $0.072 /-0.421$ \\
S3a & 0.3631 & 7.26 & 9.84 & $18.13 / 15.81$ & $-17.313 /-17.913$ \\
S3 & 1.278 & 7.26 & 9.84 & $11.85 / 9.31$ & $0.197 /-0.477$ \\
S4a & 0.3631 & 10.09 & 7.89 & $-15.94 /-13.69$ & $18.039 / 17.098$ \\
S4 & 1.278 & 10.09 & 7.89 & $-9.39 /-7.48$ & $0.548 /-0.409$ \\
\hline
\end{tabular}

Horizontal and vertical positions of collimator jaws at slip-stacking injection are shown in Table 1. Primary collimator is located in the accelerator arc $(D=1.6 \mathrm{~m})$ for the off-momentum particle interception. Each of the secondary collimators consists of a tapered part $0.3631 \mathrm{~m}$ long (S1a-S4a) with a rectangular aperture decreasing from $\mathrm{X} \times \mathrm{Y}=114.4 \mathrm{~mm} \times 63.6 \mathrm{~mm}$ to $\mathrm{X} \times \mathrm{Y}=101.6 \mathrm{~mm} \times 50.8 \mathrm{~mm}$ and a uniform part $1.278 \mathrm{~m}$ long (S1-S4) with a rectangular aperture of $\mathrm{X} \times \mathrm{Y}=101.6 \mathrm{~mm} \times 50.8 \mathrm{~mm}$. It is assumed for the calculations that the beam intensity is $5.5 \mathrm{e}+13 \mathrm{ppp}$, cycle duration is $2.2 \mathrm{~s}$ and $5 \%$ of the beam intensity is collimated at injection. Initial primary hits on the primary collimator, used for collimation system design and investigation, were accumulated during the full scale slip-stacking injection simulations described in the previous section.

Proton beam phase plane is shown in the primary and first secondary collimator in Fig. 3 for the first turn after interaction with a $0.25 \mathrm{~mm}$ tungsten primary collimator.

Particle hit distributions at slip-stacking injection in the primary and fourth secondary collimators are shown in Fig. 4. Each halo particle interacts on average 2.65 times with the primary collimator at collimation. The circulating beam with $\sigma_{d P / P}=0.0004$ as well as particles interacted with collimators and envelope of $40 \times 20 \pi \mathrm{mm} \cdot \mathrm{mrad}$ beam are shown at the entrance of collimators. Horizontal jaws of secondary collimators are located at the envelope of $40 \pi \mathrm{mm} \cdot \mathrm{mrad}$ beam. As the injection, abort and extraction Lambertson magnets are located close to the circulating beam in the Main Injector, the vertical jaws of the col-
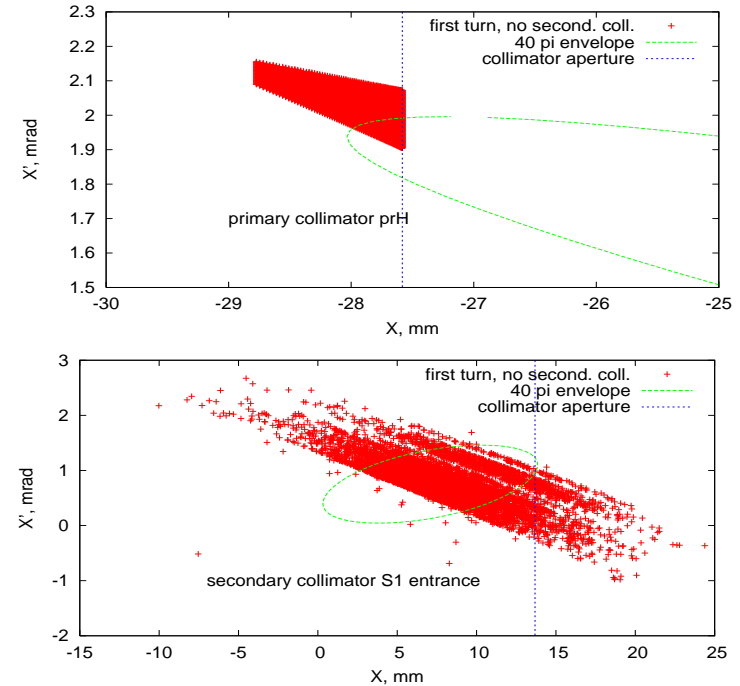

Figure 3: Phase plane at first turn after interaction with primary collimator.
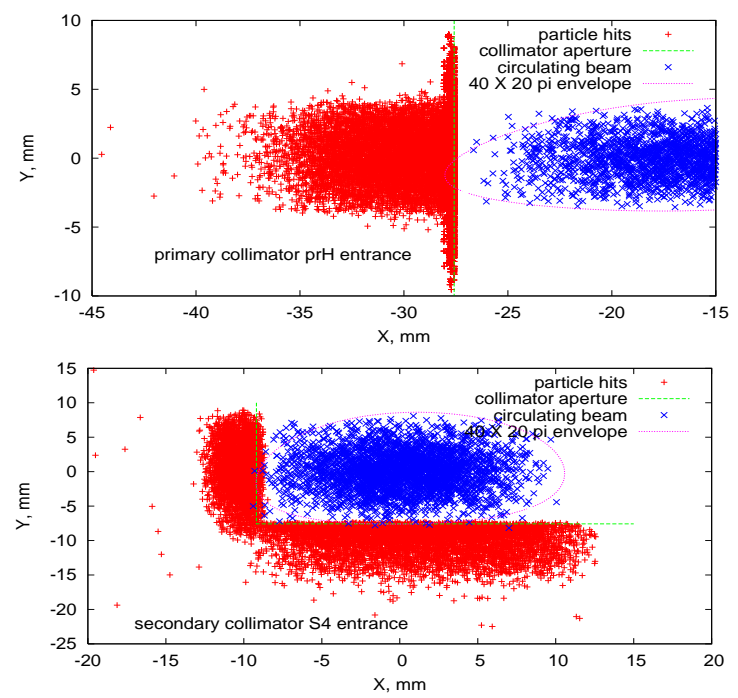

Figure 4: Particle hit distributions in the collimators.

limators are placed at $20 \pi \mathrm{mm} \cdot \mathrm{mrad}$ to reduce losses at the aperture of Lambertson magnets. The primary collimator jaw is placed $0.3 \mathrm{~mm}$ closer radially compared to the envelope defined by the radial position of the four secondary collimators.

Particle loss distributions at slip-stacking injection in the accelerator (top) and in the collimation region (bottom) are shown in Fig. 5.

The sensitivity of the collimation system to collimator position and alignment with respect to the beam is presented in Table 2. At optimal positioning of collimators, about $99.8 \%$ of beam losses are localized in the collimation region and $0.2 \%$ in the rest part of accelerator. Collimator misalignment by $1 \mathrm{~mm}$ and $0.2 \mathrm{mrad}$ causes an increased beam loss in the accelerator by a factor of 2 . 

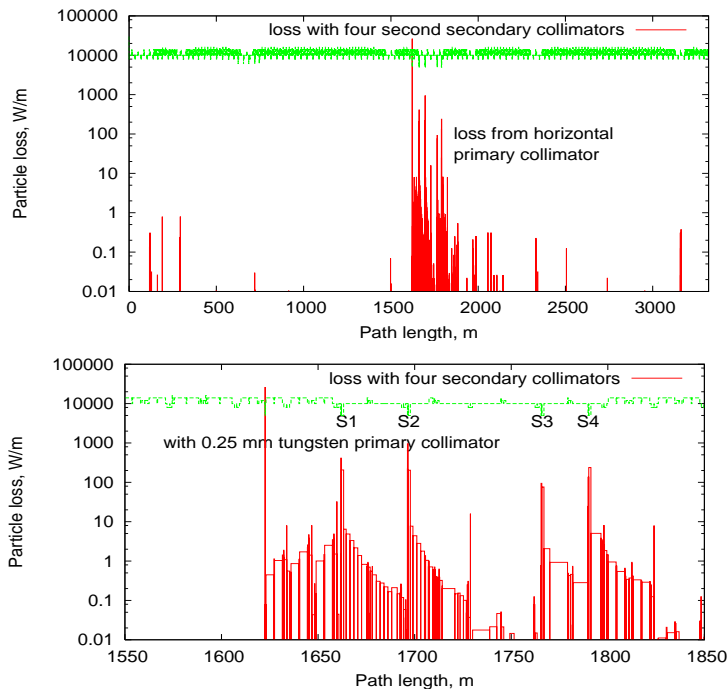

Figure 5: Particles loss distributions along the accelerator.

Table 2: Particle loss at beam collimation

\begin{tabular}{|c|c|c|c|}
\hline & \multicolumn{3}{|c|}{ beam loss, W } \\
\hline & $\begin{array}{c}\text { in collim. } \\
\text { region }\end{array}$ & $\begin{array}{c}\text { outside of } \\
\text { coll.region }\end{array}$ & $\begin{array}{c}\text { total in } \\
\text { the ring }\end{array}$ \\
\hline optimal position & 1585 & 2.497 & 1588 \\
no 1-st secondary & 1572 & 15.91 & 1588 \\
no 2-nd secondary & 1583 & 4.852 & 1588 \\
no 3-rd secondary & 1548 & 39.55 & 1588 \\
no 4-th secondary & 1576 & 12.06 & 1588 \\
\hline $\mathrm{dX}=1 \mathrm{~mm}$ at 3-rd secondary & 1585 & 3.109 & 1588 \\
$\mathrm{dY}=1 \mathrm{~mm}$ at 3-rd secondary & 1585 & 2.958 & 1588 \\
$\mathrm{dX}, \mathrm{Y}=1 \mathrm{~mm}$ at all second. & 1583 & 4.425 & 1588 \\
\hline $\mathrm{dX}, \mathrm{Y}=1 \mathrm{~mm}$ at all second. & 1582 & 5.665 & 1588 \\
$\mathrm{dX}=0.2$ mrad at all second. & & & \\
\hline & \multicolumn{3}{|l}{} \\
& &
\end{tabular}

\section{ENERGY DEPOSITION SIMULATIONS}

Energy deposition calculations for the Main Injector collimation system were performed with the MARS15 code [2]. The model includes all the essential elements with detailed description of geometry, materials and magnetic fields. The tunnel with concrete walls is surrounded by soil (see Fig. 6). The following color scheme is employed to denote materials used in the model: white, blue, grey, turquoise, red, and brown colors correspond to vacuum, air, concrete, steel, yoke, and magnet coil, respectively. The issues of surface water activation, contact residual dose around the region, and accumulated dose in magnet coils were addressed in the study. Activation of water with radionuclides is strictly limited by environmental protection regulations. Limitations on residual activation and accumulated dose in magnets are derived mostly from practical considerations.

The predicted activation of surface water outside the tunnel around the hottest spot-secondary collimator S2-is about $60 \%$ of the prescribed limit. The latter corresponds to the star density of $650 \mathrm{~cm}^{-3} \mathrm{~s}^{-1}$ averaged over a soil volume that contains $99 \%$ of all stars.

When planning on various maintenance and hands-on procedures, usually the contact residual dose is required

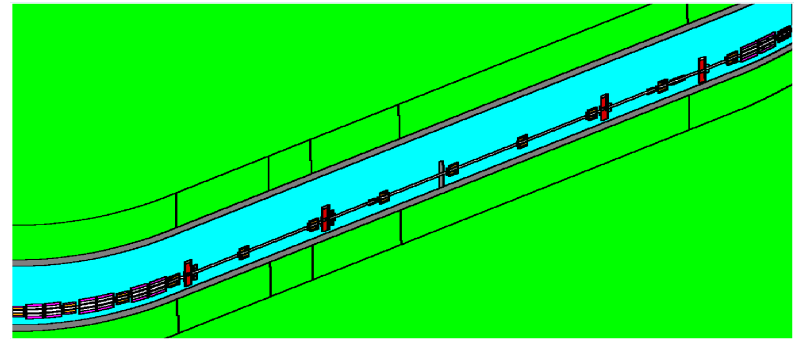

Figure 6: Plan view of the collimation region.

not to exceed $1 \mathrm{mSv} / \mathrm{hr}$. In order to reduce the residual activation, the bodies of all secondary collimators were surrounded with marble layers approximately $10 \mathrm{~cm}$ in thickness. The advantage of using the material is in its extremely low residual activation. One can see in Fig. 7 that predicted contact residual dose on tunnel walls and collimator S2 (except for its right side) does not exceed $1 \mathrm{mSv} / \mathrm{hr}$. There are several local hot spots (above the limit) on other components in the beam line between primary and first secondary collimator. Linear dimension of such a spot is about $30 \mathrm{~cm}$ and the issue can be resolved by means of a local shielding.

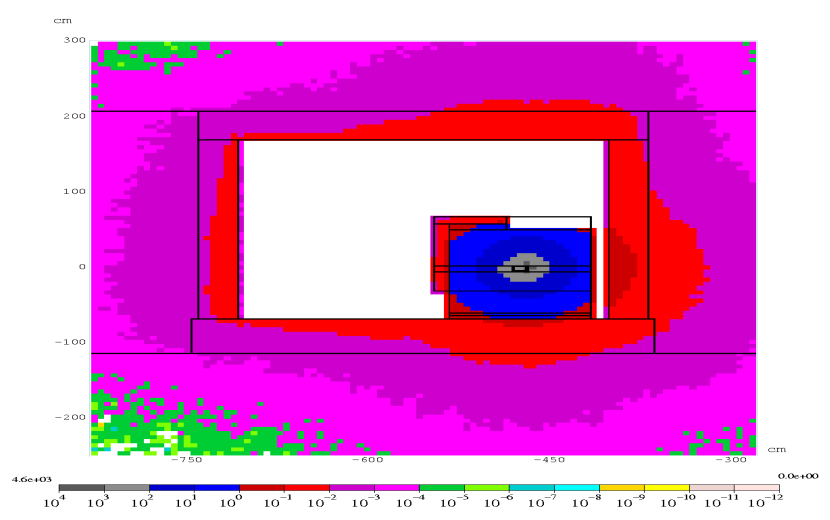

Figure 7: Calculated distribution of contact residual dose $(\mathrm{mSv} / \mathrm{hr})$ over a tunnel cross section with collimator S2.

Lifetime of a magnet depends to a great extent on accumulated dose in magnet coils. The most vulnerable material in the coils is epoxy which can survive for absorbed dose up to $4 \mathrm{MGy}$. The calculated results reveal that the highest dose load is observed for the quadrupole located upstream of collimator S1 (up to 1 MGy per year). In order to mitigate the problem, extra masks should be used in front of the magnets. For most of the other magnets the predicted accumulated dose is from 0.1 up to $0.5 \mathrm{MGy}$ per year which means magnet lifetime of 8 years and more.

\section{REFERENCES}

[1] I. S. Baishev, A. I. Drozhdin, N. V. Mokhov, X. Yang "STRUCT Program User's Reference Manual", http://www-ap.fnal.gov/users/drozhdin/

[2] N.V. Mokhov, "The MARS Code System User's Guide", Fermilab-FN-628 (1995); N.V. Mokhov, et al, "Recent Enhancements to the MARS15 Code", Fermilab-Conf-04/053 (2004); http://www-ap.fnal.gov/MARS/ 